\title{
Prevalence of vestibular dysfunction in hospitalized patients at risk of fall by Morse Fall Scale
}

\author{
Young-Soo Chang ${ }^{1}$, Seeun Son ${ }^{2}$, Jungmin Ahn ${ }^{3}$, Sang-Yeong Park², Eun J Baek ${ }^{2}$, Hey WYu² and Won-Ho Chung ${ }^{2 *}$ \\ ${ }^{1}$ Department of Otorhinolaryngology - Head and Neck Surgery, Korea University College of Medicine, Korea University Ansan Hospital, Ansan, Republic of Korea \\ ${ }^{2}$ Department of Otorhinolaryngology-Head and Neck Surgery, Samsung Medical Center, Sungkyunkwan University, School of Medicine, Seoul, Korea \\ ${ }^{3}$ Department of Otorhinolaryngology - Head and Neck Surgery, ROK Armed Forced Capital Hospital, Bundang, Korea
}

\begin{abstract}
Aim: This study aimed to assess the prevalence of vestibular dysfunction among hospitalized patients with a high risk of fall as assessed by MFS.

Background: The Morse Fall Scale (MFS) is a rapid and simple method of assessing the risk of fall that is now commonly used in the hospital.

Methods: In hospitalized patients, MFS was applied to assess the risk of fall. The cut-off value for the high-risk group was MFS score of 45 points or greater. The vestibular function assessed by video head impulse test and/or sensory organization test of dynamic posturography.

Results: Fifty-three patients were recruited. Overall, the prevalence of vestibular dysfunction was 34.48\% (10/27) in the high-risk group and 8.33\% (2/24) in the low-risk group $(\mathrm{p}=0.045)$. Patients with a past history of dizziness showed a significantly higher incidence of vestibular dysfunction $(\mathrm{p}=0.02)$.

Conclusion: In patients with a high risk of fall or the history of dizziness, the prevalence of vestibular dysfunction was significantly higher.

Implications for nursing management: Patients with high risk of fall as assessed by MFS should be thoroughly evaluated for possible vestibular dysfunction. Education and a vestibular exercise program should also be provided to these patients.
\end{abstract}

\section{Introduction}

Falls that occur in hospitalized patients constitute a serious threat to in-patient safety. Although several hospital programs for fall prevention have been implemented, patients continue to fall during hospitalization. The prevalence of falls during hospitalization varies by nursing unit type, with rates per 1,000 bed-days reported to range from 2.2 to 7 in acute care hospitals $[1,2]$ and 8.9 to 19.8 in rehabilitation hospitals [3,4]. Previous studies have reported that a total of 315,817 falls occurred (rate $=3.56$ falls $/ 1,000$ patient-days), of which $26.1 \%$ resulted in an injury (rate $=0.09 / 1,000$ patient-days) [5], and the risk of fall increases by approximately $2 \%$ during hospital stays $[6,7]$.

Prior research has suggested categorizing falls by cause as accidental, unanticipated physiologic, or anticipated physiologic falls [7]. Accidental falls are defined as falls experienced by patients whose risk "cannot be identified before the fall and do not score a risk of falling on a predictive instrument." Unanticipated physiological falls occur due to "physical conditions that cannot be predicted until the patient falls," whereas anticipated physiological falls "occur in patients whose score on the Morse Fall Scale (MFS) indicates that they are at risk of fall." Attempts to prevent anticipated physiological falls should be made using fall prevention methods during hospitalization. For this reason, in many hospitals, fall risk assessments are conducted on the admission day, and information on prevention measures are imparted to the patients. MFS has been widely accepted as the scoring system ideal for identifying patients at risk of fall [8]. According to the scale, those with a higher risk of fall have some of the following characteristics: a prior fall, weak or impaired gait, use of a walking aid, intravenous access, or impaired mental status. MFS is a rapid and simple method for assessing the risk of fall. If the risk is high, patients can be educated on protocoled preventive nursing interventions.

Several studies to date have reported that risk factors for fall occurrence include sarcopenia [9], polypharmacy [10,11], vitamin D status [12], and the presence of a concomitant sensory deficit such as peripheral neuropathy [13].

In addition, vestibular dysfunction has been significantly associated with gait speed and the risk of fall. Therefore, the assessment of the prevalence of vestibulopathy among hospitalized patients may be helpful in preventing falls in the hospital. Agrawal et al. [14] used a simple head impulse test (HIT) for the screening of vestibular impairment and suggested directing targeted vestibular therapy to reduce gait impairment and the risk of fall in older individuals. Dozza et al. [15] reported that gait improves, and the risk of fall decreases among persons with balance and vestibular disorders when using an instrumented vibrotactile vest in a gait laboratory.

If it is determined that there is a risk of falling per MFS, nurseprovided education given to patients for preventing falls is advised.

${ }^{\star}$ Correspondence to: Won-Ho Chung, Department of OtorhinolaryngologyHead and Neck Surgery, Sungkyunkwan University School of Medicine, Samsung Medical Center, 81 Irwon-ro, Gangnam-gu, Seoul, Korea, Tel: +82-23410-3579, Fax: +82-2-3410-3879; E-mail: whchung@skku.edu

Key words: falls, hospitalized, Morse Fall Scale, prevalence, vestibular dysfunction Received: March 02, 2020; Accepted: March 17, 2020; Published: March 20 2020 
Such can include several measures to prevent accidental falls such as taking precautions for falling, maintaining good environmental control, and drug management. However, vestibular screening is not usually included in this care regimen because, although vestibular dysfunction is considered a major risk factor for fall, it is not known how prevalent vestibular dysfunction is among hospitalized patients at risk of falling as assessed by MFS.

The aim of our study was thus to assess the prevalence of vestibular dysfunction in hospitalized patients according to MFS.

\section{Methods}

\section{Subjects}

From July 2017 to August 2018, we prospectively enrolled subjects aged over 40 years who were admitted to the hospital and did not suffer from any middle or inner ear diseases. Inpatient wards were randomly selected, which were the internal medicine; ear, nose, and throat; and thoracic surgery departments. Every subject was assessed initially using MFS. The details for MFS are described in table 1. Patients were divided into a high- and low-risk group. The cut-off for the high-risk group was MFS score of 45 points or more. Past medical history (i.e., hypertension and diabetes) were reviewed. The Institutional Review Board of Samsung Medical Center approved this study (IRB No. 2016-04-015).

\section{Vestibular function test}

To evaluate the vestibular function of the subject, video head impulse test (vHIT) and sensory organization tests of dynamic posturography (SOT) were conducted. The institutional review board approved this study. The functioning of the anterior, lateral, and posterior semicircular canals was assessed with vHIT testing (ICS Impulse 3-D vHIT system; GN Otometrics, Taastrup, Denmark). During the test, subjects were seated wearing goggles with their head and body facing a target lightemitting diode (LED) positioned on a wall at a distance of $1 \mathrm{~m}$. The operator, standing behind the study subject, held the subject's head and instructed the subject to look continually at a dot located on the wall. Each subject was subjected to a minimum of 10 head impulses in the three different planes to each side (left or right), with unpredictable timing and direction. vHIT testing results were considered as abnormal if there was low gain $(<0.8$ for the horizontal canal and $<0.7$ for the vertical canals) with saccades in at least one semicircular canal plane.

The SOT was assessed with computerized dynamic posturography (Balance manager, NeuroCom, CA, USA). The SOT is made up of six conditions, which assess the individual's balance performance during

Table 1. Morse Fall Scale (MFS)

\begin{tabular}{|l|l|l|}
\hline Domain & Scale & Score \\
\hline History of falling (immediate or within 3 months) & No & 0 \\
\hline Secondary diagnosis & Yes & 25 \\
\hline & No & 0 \\
\hline Ambulatory aid & Yes & 15 \\
\hline & Bed rest/nurse assist & 0 \\
\hline & Crutches/cane/walker & 15 \\
\hline Intravenous line/heparin lock & Furniture & 30 \\
\hline & No & 0 \\
\hline Gait/transferring & Yes & 20 \\
\hline & Normal/bedrest/immobile & 0 \\
\hline & Weak & 10 \\
\hline Mental status & Impaired & 20 \\
\hline & Oriented to own ability & 0 \\
\hline & Forgets limitations & 15 \\
\hline & & \\
\hline
\end{tabular}

a sequence of six increasingly difficult subtests. The subtests included combinations of eyes open, eyes closed, and conditions with a moving sway reference. In this study, the value of SOT was considered as abnormal if the vestibular score was below the reference value.

\section{Statistical analysis}

For group comparisons of continuous variables, the independent $\mathrm{t}$-test or Mann-Whitney $\mathrm{U}$ test was used as appropriate after checking normality (of baseline) via the Kolmogorov-Smirnov test. Vestibulopathy was defined if there were any abnormal results in either vHIT or SOT. For comparison of the proportion of vestibulopathy, the chi-squared test was used. Differences were considered significant when the p-value was less than 0.05 . All data were analyzed using the Statistical Package for the Social Sciences software version 20.0 (SPSS, Chicago, Illinois, USA).

\section{Results}

Fifty-three patients were recruited into this study; of these, 29 patients were stratified into the high-risk group and 24 patients were stratified into the low-risk group (Table 2). The mean ages of the groups were $66.69 \pm 12.54$ and $54.04 \pm 15.92$ years, respectively $(\mathrm{p}=$ 0002). There were 34 males (64.2\%) and 19 females (35.8 \%) in total. Among the study population, some patients who suffered from chronic illness such as hypertension $(n=17)$ and diabetes $(n=14)$. Six patients reported a history of feeling dizzy (defined as any history of a sudden occurrence of the sensation of rotation or movement of oneself or one's surroundings in any plane) in the past).

Among 53 patients, 35 underwent both vHIT and SOT, 16 underwent vHIT only, and two underwent SOT only. Among the patients who underwent vHIT, six patients in the high-risk group $(6 / 27$; $22.22 \%$ ) showed abnormal vestibular function, while none of the lowrisk patients $(0 / 24 ; 0 \%)$ showed abnormal results (Figure 1).

Among the patients who underwent SOT, six patients (6/22; $27.27 \%$ ) showed abnormal vestibular function in the high-risk group, while two of the low-risk patients $(2 / 15 ; 13.33 \%)$ showed abnormal results (Table 3).

The prevalence of vestibulopathy (abnormal vHIT or abnormal SOT results) was $34.48 \%(\mathrm{n}=10)$ in the high-risk group and $8.33 \%$ in the low-risk group $(n=2)$. This result reveals the difference in distribution had statistical significance $(\mathrm{p}=0.045)$ (Table 4).

Patients with a history of dizziness showed a higher ratio of vestibulopathy $(p=0.02)$. A history of hypertension or diabetes was not associated with vestibulopathy (Table 5).

\section{Discussion and conclusion}

This study revealed the prevalence of vestibular dysfunction in admitted patients according to the risk of fall as assessed by MFS. The prevalence of abnormal vestibular function in the high-risk group according to MFS was $22.22 \%$ per vHIT and $27.27 \%$ per SOT, respectively. When both tests' results are considered, the overall prevalence of vestibular dysfunction in the high-risk group was $34.48 \%$ higher than that in the low-risk group (10\%) and the group difference was statistically significant.

Although the sample size was small, the strengths of this study stress the clinical significance of considering hospitalized patients with vestibular dysfunction to be at risk of fall. The peripheral vestibular end-organs provide continuous input to the brain about angular and linear accelerations of the head, contributing to gaze stability and 
Table 2. Demographic data $(\mathrm{n}=53)$

\begin{tabular}{|c|c|c|c|}
\hline & $\begin{array}{l}\text { Low-risk group } \\
\quad(\mathrm{n}=\mathbf{2 4})\end{array}$ & $\begin{array}{l}\text { High-risk group } \\
\quad(\mathrm{n}=29)\end{array}$ & p-value \\
\hline $\begin{array}{l}\text { Age, years } \\
\text { Mean } \pm S D \\
\text { Median (range) }\end{array}$ & $\begin{array}{c}54.04 \pm 15.92 \\
58.0(20-73)\end{array}$ & $\begin{array}{c}66.69 \pm 12.54 \\
72(48-86)\end{array}$ & 0.002 \\
\hline \multicolumn{4}{|l|}{ Sex } \\
\hline $\mathrm{M} / \mathrm{F}$ & $18 / 6$ & $16 / 13$ & 0.16 \\
\hline \multicolumn{4}{|l|}{ Hypertension } \\
\hline Yes & 5 & 12 & \\
\hline No & 19 & 17 & 0.15 \\
\hline \multicolumn{4}{|l|}{ Diabetes mellitus } \\
\hline Yes & 3 & 11 & \\
\hline No & 21 & 18 & 0.06 \\
\hline \multicolumn{4}{|l|}{ History of dizziness } \\
\hline Yes & 0 & 6 & \\
\hline No & 24 & 23 & 0.03 \\
\hline \multicolumn{4}{|l|}{ Admitting department } \\
\hline Gastrointestinal disease & 0 & 3 & \\
\hline Pulmonology & 4 & 3 & \\
\hline Endocrinology & 0 & 1 & \\
\hline Nephrology & 0 & 8 & \\
\hline Rheumatology & 0 & 2 & \\
\hline Ear, nose, and throat & 20 & 11 & \\
\hline Thoracic surgery & 0 & 1 & \\
\hline
\end{tabular}

Table 3. Results of sensory organization test of dynamic posturography $(n=37)$

\begin{tabular}{|l|c|c|c|}
\hline & $\begin{array}{c}\text { Low-risk group } \\
(\mathbf{n = 1 0 )}\end{array}$ & $\begin{array}{c}\text { High-risk group } \\
\text { (n= 22) }\end{array}$ \\
\hline Somatosensory score & $0(0 \%)$ & $1(4.5 \%)$ \\
\hline Abnormal & $15(100 \%)$ & $21(95.5 \%)$ \\
\hline Normal & & 1.00 \\
\hline Visual score & $0(0 \%)$ & $5(22.7 \%)$ \\
\hline Abnormal & $15(100 \%)$ & $17(77.3 \%)$ \\
\hline Normal & & \\
\hline Vestibular score & $2(13.3 \%)$ & $6(27.3 \%)$ \\
\hline Abnormal & $13(86.7 \%)$ & $16(72.7 \%)$ \\
\hline Normal & & 0.07 \\
\hline
\end{tabular}

Table 4. Prevalence of vestibulopathy depending on risk group assessing with MFS $(\mathrm{n}=53)$.

\begin{tabular}{|l|c|c|c|}
\hline & $\begin{array}{c}\text { Low-risk group } \\
(\mathbf{n}=\mathbf{2 4})\end{array}$ & $\begin{array}{c}\text { High-risk group } \\
(\mathbf{n}=\mathbf{2 9})\end{array}$ \\
\hline vHIT (n=37) & & 6 \\
\hline Vestibulopathy & 0 & 21 \\
\hline Normal & 24 & \\
\hline SOT (n=32) & & 6 \\
\hline Vestibulopathy & 2 & 16 \\
\hline Normal & 13 & 0.02 \\
\hline Overall results & & 16 \\
\hline Vestibulopathy & 2 & 10 \\
\hline Normal & 22 & 19 \\
\hline
\end{tabular}

Table 5. Prevalence of vestibulopathy depending on medical history $(n=53)$

\begin{tabular}{|c|c|c|c|}
\hline & $\begin{array}{l}\text { Vestibulopathy } \\
\quad(n=12)\end{array}$ & Normal vestibular function $(n=41)$ & p-value \\
\hline \multicolumn{4}{|c|}{ Hypertension } \\
\hline Yes & 5 & 12 & \\
\hline No & 7 & 29 & 0.49 \\
\hline \multicolumn{4}{|c|}{ Diabetes mellitus } \\
\hline Yes & 3 & 11 & \\
\hline No & 9 & 30 & 1.0 \\
\hline \multicolumn{4}{|c|}{ History of dizziness } \\
\hline Yes & 4 & 2 & \\
\hline No & 8 & 39 & 0.02 \\
\hline
\end{tabular}


A

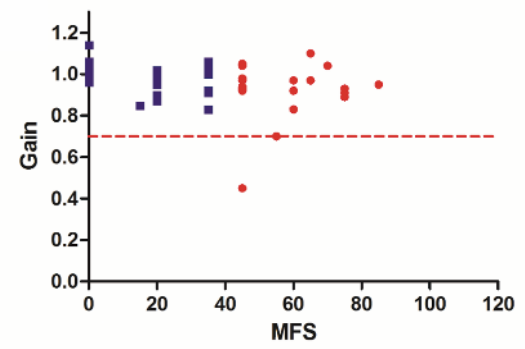

D

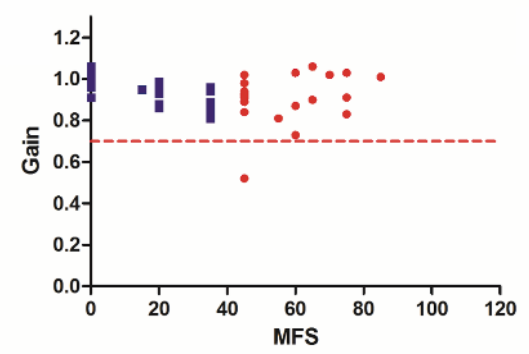

B

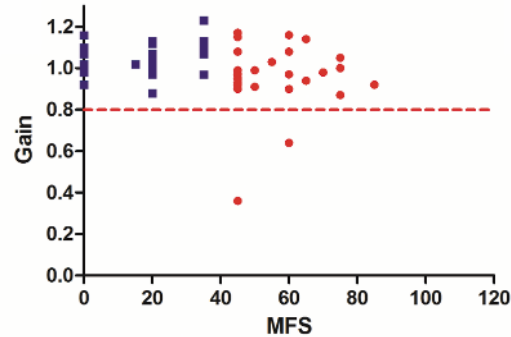

E

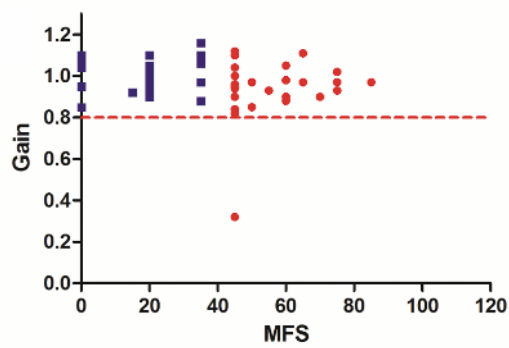

C

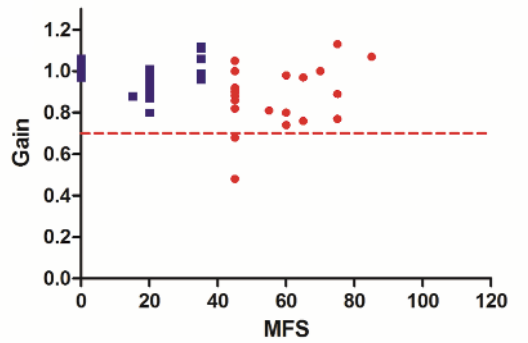

- High-risk group

- Low-risk group

Figure 1. Results of vHIT according to the MFS; (A) right anterior canal, (B) right lateral canal, (C) right posterior canal, (D) left anterior canal, (E) left lateral canal, and (F) left posterior canal.

body balance during head movements through the vestibule-ocular reflex (VOR) and vestibule-spinal reflex [16]. Characteristic features of gait disorders in patients with vestibular deficits or cerebellar ataxia include increased levels of spatiotemporal gait variability in the foreaft and medio-lateral gait dimension. This feature is associated with an increased risk of fall in both patients with vestibular hypofunction as well as patients with cerebellar ataxia [17]. Considering gait variability is linked to the risk of fall, early assessment and appropriate preventive management for hospitalized patients with vestibulopathy are crucial.

In many hospitals, the risk of fall is commonly assessed using MFS. MFS is a simple scoring system designed to identify patients at risk of falling [18]. If patients are determined to be at high risk of fall by MFS, then nursing care aimed at fall prevention is initiated. This usually includes passive measures to prevent falls such as taking precautions against falling and increasing environmental control. In addition, using caution regarding administering drugs that increase the risk of fall (FRIDs) during prescribing should be considered in the high-risk group after assessing with MFS. The most common FRIDs are different types of psychotropic drugs, such as sedatives, hypnotics, antidepressants, and antipsychotic medications, which can cause sedation, impaired balance, and coordination, thereby increasing the risk of fall [19]. Therefore, patients should be assessed on the first day of hospitalization regarding their risk for fall and an intensive fall-prevention protocol be implemented where appropriate. However, in our study, we demonstrated the high prevalence of vestibular dysfunction in those at high risk of fall as assessed by MFS and stressed the role of MFS as a screening tool for fall prevention. Our research implies that patients determined as being at high risk per MFS need to receive intensive precaution and active prevention management interventions regarding vestibular dysfunction to prevent falls. Vestibular rehabilitation is known to be helpful among patients with vestibular disorders of all ages.

A previous study demonstrated that vestibular rehabilitation in elderly persons with multisensory dizziness improved their ability to stand on one leg with closed eyes and to walk on a line [20]. This result suggests that vestibular rehabilitation is a feasible treatment for deployment among elderly patients with vestibulopathy to prevent falls.

In addition, the evaluation of the history of dizziness is essential when assessing for vestibular dysfunction. A dizzy feeling is an important clinical manifestation of vestibular dysfunction; therefore, it should be looked for especially in patients at high risk of fall. This information provokes additional caution to prevent falls in hospitalized patients.

We used two tests to screen vestibular dysfunction in the patients. The vHIT has been used previously as a clinical tool with high diagnostic value in evaluating vestibular function. It is easily deployed and can yield an objective assessment of the function of the VOR in each semicircular canal. The vHIT records slow-phase eye movements to assess the VOR. The VOR gain and corrective saccades are analyzed quantitatively [21-24]. VOR gain is the most reliable means to assess the vestibular status. The normal value of VOR gain by vHIT has been reported on extensively [21,24-27] and is slightly decreased with increasing age. The cutoff values of gain are 0.8 in the lateral canal and 0.7 in the vertical canal, respectively. In our data, $22.22 \%(6 / 27)$ of patients in the high-risk group showed the vHIT gain value under the reference cutoff values. However, there was no patient who showed an abnormal gain in the low-risk group.

The SOT test is a form of posturography that is designed to assess quantitatively an individual's ability to use visual, proprioceptive, and vestibular cues to maintain postural stability in stance [28]. In the equilibrium score, abnormal scores in the somatosensory, visual, and vestibular subsets were found in $4.5 \%, 22.7 \%$, and $27.3 \%$ of patients, respectively. These findings might be related with other medical conditions, such as underlying disease, aging, musculoskeletal problems, or visual problems. However, these low SOT scores might also be related with the risk of fall. In addition, two patients with vestibular subset abnormality per SOT also showed a lower gain in vHIT. This means that these two patients experienced peripheral vestibular dysfunction. 
This study has some limitations. First, the sample size in this study was small as a result of administering two different vestibular function tests to the patients admitted to the hospital for the treatment of other diseases. To assess patients according to MFS, the eligibility criterion of age was set as 40 years or older. In addition, the small sample size limits the evaluation of the association between the vestibular function test results and MFS score. Second, eligibility for inclusion in the present study was limited to some selected in-patient units, so there may be some selection bias at play. Further, some patients chose not to undergo vestibular function tests because they did not suffer any history of dizziness. This may affect the overestimation of vestibulopathy in the study. Finally, in the present study, we observed a statistical difference of the mean age according to MFS risk group. This should be noted when interpreting the results. However, we assessed the low-risk patients and the result showed a statistically significant difference. Further research with larger sample sizes would be beneficial to demonstrate the prevalence of vestibulopathy and the role of MFS in hospitalized patients.

In summary, among patients with a high risk of fall as assessed by MFS, the prevalence of vestibulopathy was higher in hospitalized patients at greater risk of fall. Therefore, MFS can be used meaningfully to evaluate the risk of fall. Patients who are at high risk of fall as assessed by MFS should be thoroughly evaluated for possible vestibular dysfunction.

\section{References}

1. Lane AJ (1999) Evaluation of the fall prevention program in an acute care setting. Orthop Nurs 18: 37-43. [Crossref]

2. Roberts BL (1993) Is a stay in an intensive care unit a risk for falls? Appl Nurs Res 6: 135-136. [Crossref]

3. Nyberg L, Gustafson Y (1995) Patient falls in stroke rehabilitation. A challenge to rehabilitation strategies. Stroke 26: 838-842.

4. Nyberg L, Gustafson Y (1996) Using the Downton index to predict those prone to falls in stroke rehabilitation. Stroke 27: 1821-1824. [Crossref]

5. Bouldin EL, Andresen EM, Dunton NE, Simon M, Waters TM, et al. (2013) Falls among adult patients hospitalized in the United States: prevalence and trends. $J$ Patient Saf 9: 13-17. [Crossref]

6. Morse JM (2002) Enhancing the safety of hospitalization by reducing patient falls. $\mathrm{Am}$ J Infect Control 30: 376-380. [Crossref]

7. Rubenstein LZ, Josephson KR (2002) The epidemiology of falls and syncope. Clin Geriatr Med 18: 141-158. [Crossref]

8. Morse JM, Morse RM, Tylko SJ (1989) Development of a scale to identify the fallprone patient. Can J Aging 8: 366-377.

9. Landi F, Liperoti R, Russo A, Giovannini S, Tosato M, et al. (2012) Sarcopenia as a risk factor for falls in elderly individuals: results from the ilSIRENTE study. Clin Nutr 31: 652-658. [Crossref]

10. Kojima T, Akishita M, Nakamura T, Nomura K, Ogawa S, et al. (2011) Association of polypharmacy with fall risk among geriatric outpatients. Geriatr Gerontol Int 11: 438-444. [Crossref]
11. Kojima T, Akishita M, Nakamura T, Nomura K, Ogawa S, et al. (2012) Polypharmacy as a risk for fall occurrence in geriatric outpatients. Geriatr Gerontol Int 12: 425-430. [Crossref]

12. Broe KE, Chen TC, Weinberg J, Bischoff-Ferrari HA, Holick MF, et al. (2007) A higher dose of vitamin $\mathrm{d}$ reduces the risk of falls in nursing home residents: a randomized, multiple-dose study. J Am Geriatr Soc 55: 234-239. [Crossref]

13. Schniepp R, Schlick C, Schenkel F, Pradhan C, Jahn K, et al. (2017) Clinical and neurophysiological risk factors for falls in patients with bilateral vestibulopathy. $J$ Neurol 264: 277-283. [Crossref]

14. Agrawal Y, Davalos-Bichara M, Zuniga MG, Carey JP (2013) Head impulse test abnormalities and influence on gait speed and falls in older individuals. Otol Neurotol 34: 1729-1735. [Crossref]

15. Dozza M, Wall C, 3rd, Peterka RJ, Chiari L, Horak FB (2007) Effects of practicing tandem gait with and without vibrotactile biofeedback in subjects with unilateral vestibular loss. J Vestib Res 17: 195-204. [Crossref]

16. Baloh RW, Honrubia V (2001) Clinical neurophysiology of the vestibular system. Oxford University Press, USA.

17. Schniepp R, Mohwald K, Wuehr M (2017) Gait ataxia in humans: vestibular and cerebellar control of dynamic stability. J Neurol 264: 87-92. [Crossref]

18. Morse JM, Morse RM, Tylko SJ (1989) Development of a scale to identify the fallprone patient. Canadian J Aging 8: 366-377.

19. Milos V, Bondesson A, Magnusson M, Jakobsson U, Westerlund T, et al. (2014) Fall risk-increasing drugs and falls: a cross-sectional study among elderly patients in primary care. BMC Geriatr 14: 40 .

20. Hansson EE, Mansson NO, Ringsberg KA, Hakansson A (2008) Falls among dizzy patients in primary healthcare: an intervention study with control group. Int $J$ Rehabil Res 31: 51-57. [Crossref]

21. Weber KP, Aw ST, Todd MJ, McGarvie LA, Curthoys IS, et al. (2008) Head impulse test in unilateral vestibular loss: vestibulo-ocular reflex and catch-up saccades. Neurology 70: 454-463. [Crossref]

22. Park JS, Kim CH, Kim MB (2018) Comparison of Video Head Impulse Test in the Posterior Semicircular Canal Plane and Cervical Vestibular Evoked Myogenic Potential in Patients With Vestibular Neuritis. Otol Neurotol 39: e263-e268. [Crossref]

23. Macdougall HG, McGarvie LA, Halmagyi GM, Curthoys IS, Weber KP (2013) The video Head Impulse Test (vHIT) detects vertical semicircular canal dysfunction. PLoS One 8: e61488. [Crossref]

24. MacDougall HG, Weber KP, McGarvie LA, Halmagyi GM, Curthoys IS (2009) The video head impulse test: diagnostic accuracy in peripheral vestibulopathy. Neurology 73: 1134-1141. [Crossref]

25. Matino-Soler E, Esteller-More E, Martin-Sanchez JC, Martinez-Sanchez JM, PerezFernandez N (2015) Normative data on angular vestibulo-ocular responses in the yaw axis measured using the video head impulse test. Otol Neurotol 36: 466-471. [Crossref]

26. Yang CJ, Lee JY, Kang BC, Lee HS, Yoo MH, et al. (2016) Quantitative analysis of gains and catch-up saccades of video-head-impulse testing by age in normal subjects. Clin Otolaryngol 41: 532-538. [Crossref]

27. Aw ST, Halmagyi GM, Haslwanter T, Curthoys IS, Yavor RA, et al. (1996) Threedimensional vector analysis of the human vestibuloocular reflex in response to highacceleration head rotations. II. responses in subjects with unilateral vestibular loss and selective semicircular canal occlusion. J Neurophysiol 76: 4021-4030. [Crossref]

28. Clendaniel RA (2000) Outcome measures for assessment of treatment of the dizzy and balance disorder patient. Otolaryngol Clin North Am 33: 519-533. [Crossref]

Copyright: (C2020 Young-Soo Chang. This is an open-access article distributed under the terms of the Creative Commons Attribution License, which permits unrestricted use, distribution, and reproduction in any medium, provided the original author and source are credited. 